\title{
Facilitation of recall by structure in serially presented nonsense strings
}

\author{
DANIEL C. O'CONNELL, CATHERINE L. STUBBS, and MARY \\ ANN THEBY, Saint Louis University, St. Louis, Missouri
}

Serial presentation of nonsense strings with immediate written recall was studied in a 3 by 2 factorial design: structure (none, morphology, morphology and syntax) and rate of presentation (1 and $3 \mathrm{sec}$ (item). Only the main factors were significant; recall was facilitated by structure and by the slower presentation rate.

Facilitation by structure in nonsense strings was studied by Epstein (1961, 1962). The earlier experiment used whole presentation and showed superior recall in strings with function words and morphological and syntactic structure, as compared with unstructured strings; the second study showed the suppression of the effect with serial anticipation. This suggested to Epstein the absence of chains of immediate probabilistic associations (which should have preserved facilitation with serial anticipation) and the importance of whole presentation for the perception of the unity of a string.

Since Epstein had also found structural facilitation with semantically anomalous word strings, Wales (1964) repeated the 1962 design, using both meaningful grammatical and anomalous strings and presentation rates of .8 and $2 \mathrm{sec} /$ item. At the slower rate, significant differences between grammatical and ungrammatical strings for normal and anomalous strings were reduced and disappeared respectively.

Epstein \& Arlinsky (1965) used semantically anomalous strings. With serial presentation ( $2 \mathrm{sec} /$ item), the superiority of syntactic over unsyntactic material disappeared. The response mode was not serial anticipation, but free recall after serial or whole presentation. Ordered response mode was adopted by Salzinger \& Eckerman (1967), who reverted to nonsense syllables. With serial presentation ( $1 \mathrm{sec} /$ item), the effect was suppressed only in declarative, not passive negative interrogative strings. The authors rejected Epstein's conclusion that chains of immediate probabilistic associations were not operative.

Several studies have obtained variant results. Simpson (1965) found that, when Ss learned a list of 30 words by serial anticipation, increasing approximation to sentence word-order led to faster learning. Denner (1966) found that serial tachistoscopic presentation of words with and without sentence structure showed structural facilitation in a reaction-time search task for specified items. O'Connell, Turner, \& Onuska (1968) used oral presentation of nonsense strings. Since oral presentation is of necessity serial, the presence of structural facilitation in intonated but not monotone strings was not in accord with Epstein's results.

Osgood (1963, p. 282), commenting on Epstein's (1962) results, suggested that, since $2 \mathrm{sec} /$ item was slower than the normal rate for reading, Ss reacted to the series as unrelated items, so that sequential syntactic habits were largely obliterated.

Salzinger \& Eckerman (1967) called attention to the difference of response mode in Epstein (1962, Experiment 2) compared with other studies, including Epstein (1962, Experiment 1). Pronunciation of each item introduced a number of changes: The response mode became serialized rather than whole; and phonemic, whereas the stimulus materials were graphemic; and they in turm were broken up by serial interjection of response items.

In the present experiment, we hypothesized that suppression of structural facilitation was a function of the response mode used by Epstein. Using ordered recall after serial presentation, we predicted structural facilitation. Since the shorter interitem interval ( $1 \mathrm{sec} /$ item) simulated a normal reading rate and the whole presentation method more closely than did the longer ( 3 sec/item), we predicted more facilitation with the shorter interval (a structure by rate interaction).

\section{STIMULI}

The stimulus materials of Bryk \& O'Connell (1967) were used, since structural facilitation had already been shown with them in a design like that of Epstein (1961). Each string consisted of 10 nonsense words comprising $\mathbf{4 0}$ graphemes. All strings were equated for number of graphemes in each word at each position. The high structure string (morphology and syntax) was: The haky deebs reciled $u$ dison a flutest pava kex; the low structure string (morphology) was: kex haky dison flutest a deebs u reciled pava the; the no structure string was: tah pava sdeeb festlut $u$ dison e leirdec hyka kex. Each was printed around the periphery of a cardboard wheel so that, as it was rotated, successive items appeared in a horizontally oriented window cut in a second cardboard circle.

\section{SUBJECTS}

The Ss were 60 men and women, students at Saint Louis University. Volunteers were randomly assigned to experimental groups in a 3 by 2 (Structure by Rate of Presentation) factorial design and run individually. The experiment was originally run with $30 \mathrm{Ss}$ and then replicated.

\section{PROCEDURE}

All Ss received instructions to learn the entire string in the correct order. Each $S$ was shown beforehand a sample string containing the type of items to be used in the experiment. He then received one of the strings at 1 or $3 \mathrm{sec} /$ item and wrote the string on a sheet of paper under instructions to indicate omissions by dashes. The response interval was unpaced. This procedure was repeated until $S$ reached a criterion of one perfect recall, i.e., the 10 items spelled correctly and in correct order.

\section{RESULTS}

Mean trials to criterion for Experiments 1 and 2 are given in Table 1. The combined means are illustrated in Fig. 1. A 3 by 2 (Structure by Rate of Presentation) factorial analysis of variance was made for each experiment. In Experiment 1, both main effects were significant: Structure $(F=4.88$, $\mathrm{df}=2 / 24, \mathrm{p}<.025)$ and Rate $(F=6.85, \mathrm{df}=1 / 24, \mathrm{p}<.025)$. In Experiment 2, only Structure was significant $(F=6.52, \mathrm{df}=2 / 24, \mathrm{p}<.01)$. A combined analysis yielded significance for Structure $(F=10.47$, $\mathrm{df}=2 / 54, \mathrm{p}<.005)$ and Rate $(\mathrm{F}=10.15, \mathrm{df}=1 / 54, \mathrm{p}<.005)$. In none of these analyses was the structure by rate interaction significant.

In all these analyses, Duncan's multiple range test revealed that high and low structure both yielded significantly better recall than no structure, but were not significantly different from one another.

\section{DISCUSSION}

Structural facilitation was clearly obtained with serial presentation. The multiple comparisons and Fig. 1 reveal the pattern of facilitation to be the same as was found by Bryk \& O'Connell (1967) with whole presentation. The overall means for the two studies were 4.7 and 4.5 trials to criterion respectively. Serialized presentation evidently did not result in a notable increase in difficulty.

The presence of structural facilitation also strongly suggested that Epstein's (1962) findings were due to the particular response mode used by him, not to serialization of the strings as such.

Table 1

Mean Trials to Criterion

\begin{tabular}{|c|c|c|c|c|}
\hline \multirow[t]{2}{*}{ Structure } & \multicolumn{2}{|c|}{ Experiment 1} & \multicolumn{2}{|c|}{ Experiment 2} \\
\hline & $1 \mathrm{Sec}$ & $3 \mathrm{Sec}$ & $1 \mathrm{Sec}$ & $3 \mathrm{Sec}$ \\
\hline No & 7.0 & 6.0 & 6.2 & 4.8 \\
\hline Low & 5.4 & 3.2 & 4.4 & 3.8 \\
\hline High & 5.2 & 2.8 & 3.8 & 3.4 \\
\hline
\end{tabular}




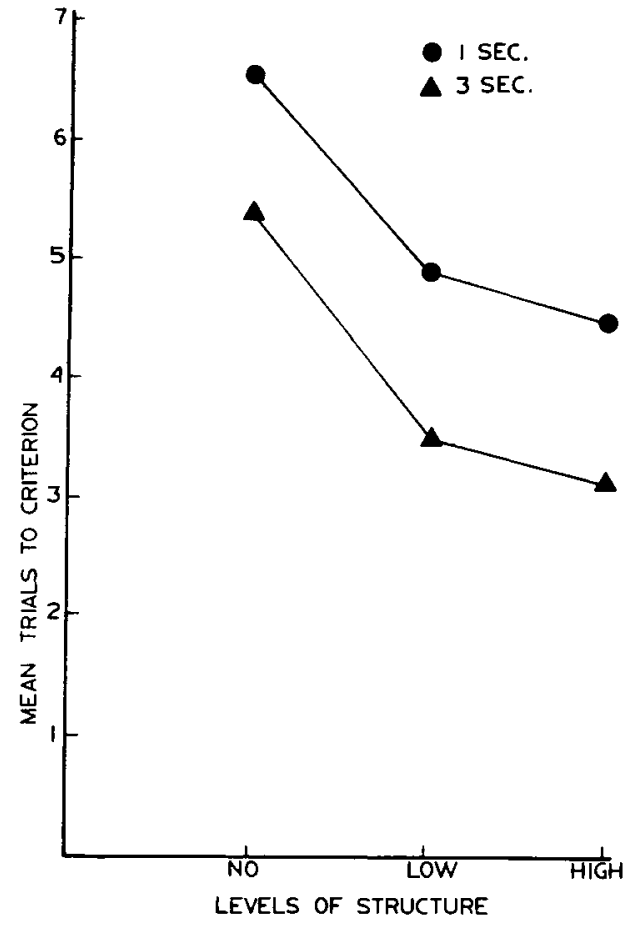

Fig. 1. Mean trials to criterion for combined data.

The influence of rate of presentation was not as predicted. The slower rate, predicted to be relatively inhibitory of structural facilitation (a structure by rate interaction). showed the same pattorn of facilitation as both the faster rate and whole prescutation (Bryk \& O'Connell. 1967). Serialization at a slower rate clearly did not adversely affect structural facilitation.

A rough comparison of the total available viewing time with 1 sec/iten, whole presentation (Bryk \& O'Connell, 1967), and 3 sec/item showed 10,20 , and $30 \mathrm{sec} / \mathrm{string}$. The respective mean trials to criterion were 5.2, 4.5, and 4.0. Since the slower rate, predicted to be inefficient. proved the most efficient, the relevance of total available viewing time can hardly be overlooked.

The evidence of the present research and of Bryk \& O'Connell (1967) and O'Connell, Turner, \& Onuska (1968) localized structural facilitation in nonsense strings at the level of morphology: the role of syntax as such was found to be minor. The results do not support the generality of Epstein's (1962) findings.

\section{REFERENCES}

BRYK, J. A., \& O'CONNELL, D. C. Immediate recall as a function of grammatical structure and mode of presentation. Psychonomic Science, $1967,8,437-438$.

DENNER, B. Perceptual processing of syntactically structured and unstructured strings. Perceptual \& Motor Skills, 1966, 23, 1310.

EPSTEIN, W. The influence of syntactical structure on learning. American Journal of Psychology, 1961, 74, 80-85.

EPSTEIN, W. A further study of the influence of syntactical structure on learning. American Journal of Psychology, 1962, 75, 121-126.

EPSTEIN, W., \& ARLINSKY, M. The interaction of syntactical structure and learning instructions. Psychonomic Science, 1965, 3, 59-60.

O'CONNElL, D. C., TURNER, E. A., \& ONUSKA, L. A. Intonation, grammatical structure, and contextual association in immediate recall. Journal of Verbal Learning \& Verbal Behavior, 1968, 7, 110-116.

OSGOOD, C. E. Psycholinguistics. In S. Koch (Ed.), Psychology: A study of a science. Vol. 4. New York: McGraw-Hill, 1963. Pp. 244-316.

SALZINGER, K., \& ECKERMAN, C. Grammar and the recall of chains of verbal responses. Journal of Verbal Learning \& Verbal Behavior, 1967, 6, 232-239.

SIMPSON, W. E. Effects of approximation to sentence word-order and grammatical class upon the serial learning of word lists. Journal of Verbal Learning \& Verbal Behavior, 1965, 4, 510-514.

WALES, R. J. Problems of repetition in verbal learning. Paper presented to the British Psychological Society, London, England, 1964. 